\title{
Stakeholders' Participation in Environmental Management in the Nigerian University System: Gender Perspective
}

\author{
Olaoluwa Paul Aasa* Olayinka Modupe Ajayi Victoria Oluwatunbi Ogunjobi \\ Oluwaseun Tope Akinbogun \\ Department of Project Management Technology, Federal University of Technology, Akure, \\ P.M.B 704, Ondo State, Nigeria
}

\begin{abstract}
The study assessed stakeholders' participation in environmental management in the university system in Nigeria from a gender perspective. A sample size of 386 respondents in The Federal University of Technology, Akure, Nigeria provided answers to questions asked on the study. Kruskal-Wallis test results showed that the level of participation in energy saving activities is high for both male and female respondents. Female stakeholders show a moderately level of participation in efficient transportation and waste management activities while the male show high level of participation for waste management and moderately participation for efficient transportation. Consequently, the study advocated for periodic training for all stakeholders on university campus irrespective of their gender to equip them with knowledge and skills needed to participate in environmental management.

Keywords: Environmental Management, Gender, University system, Stakeholders' participation. Environmental protection

DOI: $10.7176 / \mathrm{JESD} / 10-24-11$
\end{abstract}

Publication date: December $31^{\text {st }} 2019$

\section{Introduction}

Issues of global warming, climate change have been very prominent in recent times (Adebo \& Ajewole, 2012) as they affect the planet that houses humanity. Governments all over the world are challenged by the global and national dimensions of increase in these environmental problems. Natural disasters are becoming more frequent and more intense, and the impact of population growth on scarce resources raise the possibility of environmental degradation (Aye, 2017). The need to protect the environment hence becomes imperative (Chukwu, 2014). In Nigeria, there is an increasing level of environmental concern and awareness. The right to the environment has now become the right to live. People need nature and nurture to live, and to live they have to produce and to consume while wastes are being generated from the by-products of consumption (Adebo \& Ajewole, 2012).

The university community is a beehive of activities that increase the footprints on the environment most especially in the areas of transportation, energy usage and other resource usages. Fortuitously, operations within the university system such as training/teaching, research, campus operations and community services (Aasa, 2019) can help in reducing these impacts. Global University Network for Innovation (GUNI) observed that environmental sustainability in universities takes the form of research, curricula, community engagement, and facilities operations (GUNI, 2012 as cited in Vaughter, et al., 2013). University stakeholders comprising of students, staff and service providers will be involved and affected when such decisions are taking in response to the environmental concerns.

The importance of gender to environmental issues has been a frontline discourse since the early 1970s, when the growing debate on environmental changes intersected with the emergence of studies on women's roles in development and development policy strategies within the international women's rights movement (Global Environment Facility, 2009 in European Institute for Gender Equality (EIGE), 2016). In the absence or lack of consideration for gender balance, it may be difficult for an organization to achieve its growth (Wittenberg-Cox, 2014 as cited in Kassinis, et al., 2016).

Most times when gender equality issues are being raised, emphases are always on inadequate women participation relative to the men folks. Debates relating to women's participation in environmental management have emphasized women's participation. An instance is the program areas of Agenda 21, which incorporated the role of women. In the same discourse, Principle 20 of the Rio Declaration states that "women have a vital role in environmental management and development. Their full participation is therefore essential to achieving sustainable development." (Aye, 2017). This has the implication that both men and women have a collegial role for sustainable development path. As such, attention is being paid on gender sensitivity in the field of environmental protection. A more common view is that more women than men have a positive attitude towards environmental issues (Chukwu, 2014). Notwithstanding, gender equality is achieved when women and men, girls and boys, have equal rights, life prospects and opportunities, and the power to shape their own lives and contribute to society (Sida, 2016).

Ensuring sustainability implies making all the stakeholders have the rights to participate in the activities involved. Over the past three decades, Castaneda, Aguilar and Rand (2013) observed that international agreements, 
national policies, and other reporting instruments have identified the correlation among gender, the environment, and sustainable development. The overall implementation of mechanisms for advancing gender equality, environmental protection, and sustainable development has been weak.

Equally, gender is a distinguishing factor in determining human relationships with the environment. Women and men have different responsibilities, knowledge, and needs in relation to natural resources (IUCN, 2013). Therefore, there is also the need to understand the various ways male and female are involved in environmental management initiatives with a view to ensuring a participatory approach to environmental protection programmes. Therefore, this study assessed stakeholders' participation in environmental management in the university system in Nigeria from a gender perspective.

\section{Review Of Literature}

\subsection{Environment Sustainability: Gender Perspective}

As the population grows and the economy progresses, demand for basic needs and consumer goods rises as well. The increase in population places greater demands on natural resources thus affecting the environment (Aye, 2017). Increasing population is enough reason to seek to reduce ecological footprint driving forces through increased efficiency in the use of resources (Thomas, Eugene, \& Richard, 2007). The earth atmosphere is the fundamental resource on which people rely for prosperity. Gender norms influence the impact of people on the environment, the impact of environmental degradation on people, and access to and power over natural resources (Gender Tool Box, 2016).

Traditionally, gender roles reflecting men's participation in commercial spheres and women's in domestic spheres have not favoured women's ability to engage in environmental decision making. Men, more often than women, use natural resources commercially, which contributes to the formal economy, making men's activities more visible to policymakers, economists, scientists, and planners (Luna, et al., 2015). When addressing gender in the context of the environment, it is important to recognise that women and men are not homogenous groups. Where women and men live, their age, social class, ethnicity, religion, sexual orientation and other variables, interact in shaping the links between gender and the environment. This complexity must be accounted for in participation, needs analysis and programme design (Sida, 2016). Taking gender into consideration provides better guidance for women and men who are building adaptive capacity in places where inhabitants depend on rain-fed agriculture and natural resources - they are the most vulnerable to climate change (Lambrous \& Piana, 2006 in Agwu \& Okhimamhe, 2009).

Due to different roles women and men play in households, the economy, and environmental sustainability in most societies, enhancing gender equality is integral to ensuring a balanced approach to the economic, social and environmental dimensions of sustainable development and to achieving all other SDGs (OECD, 2019). The gender-sustainability relationship can be understood by recognizing, on the one hand, women's positive impacts on sustainable development, and, on the other hand, the extent to which slow progress on sustainable development affects the condition of women and hampers gender equality (OECD, 2019). Ensuring women's perspectives, experiences and needs (like their male counterpart) inform policymaking is critical for sustainable development and improving livelihood outcomes. Often, women are viewed as vulnerable victims to the effects of climate change, and their contributions to environmental decision-making and natural resource management are overlooked and ignored (Prebble, 2015).

Therefore, a gender analysis of environmental management is necessary, looking at gender aspects of the use of natural resources (water, forests, land, etc.), consumption of services and goods (transport, food, etc.) and experiences of environmental degradation (pollution, chemicals, loss of biodiversity, etc.). Women and men should be agents in environmental management, including equal participation in decision making and policy processes (Gender Tool Box, 2016).

\subsection{Empirical Studies}

Alpay, et al. (2010) considered gender issues in the university research environment. Focus groups were used to examine the attitudes and experiences of females in four main skill areas: group work; communication; personal awareness; project planning and management. The study indicated that consistent female concerns on issues pertaining to effective female role models, negative work-role stereotypes and the work-life balance of an academic career. For all four skill areas, the average confidence scores of the female participants fell below those of males, but these differences were only statistically significant for perceptions on group work and communication skills and prior to an intense skills development course.

Investigating the gender differences in pro-environmental attitudes and behaviours, Plavsic (2013) found university females reporting more favourable and appreciative attitudes towards the environment. Generally, the university stakeholders were being influenced by the social norms of their family, friends, and other students' perceived pro-ecological behaviours.

Sivamoorthy, Nalini, and Kumar (2013) evaluated environmental awareness and practices relating to various 
factors like causes of pollution, conservation of soil, forest, air, etc., energy conservation, conservation of human health, conservation of wildlife and animal husbandry. The target for their study were college students as environmental education is part of their curriculum. The study shows that the level of awareness was generally high among the respondents but in practice, males were more involved than females.

A longitudinal comparison of sustainability learning between men and women in engineering and nursing programmes shows that engineering programmes and gender affect actions positively with engineering students increasing their sustainability performance significantly more than nursing students (Haartman, et al., 2017).

Akkor and Gunduz (2018) piloted a study to detect the attitude and behaviour levels of university students about environmental education. Female students have higher environmental attitudes and they are more sensitive to the environment than male students were, but environmental awareness was generally low which supports some previous studies on the subject matter.

The foregoing underpinned mixed realities regarding environmental management decisions among male and female students on the university campus. This study, therefore, discovers the gap in the literature regarding a participatory approach to environmental decisions from the perspectives of male and female stakeholders in the university system.

\section{Methodology}

\subsection{Population and Sample}

A sample size of 386 derived using Krejcie and Morgan (1973) table was selected from a population of 21,512 in The Federal University of Technology, Akure (FUTA), Ondo State, Nigeria. The institution is the only Federal University of Technology located in the Southwest of Nigeria. Sample selection was through stratified sampling technique of stakeholders in the study area. The entire population was divided into three subgroups (students, staff and commercial service providers) after which appropriate proportions as shown in Table 1 were purposively selected from each subgroup.

Table 1: Population and sample size

\begin{tabular}{|l|r|r|r|}
\hline Stakeholders & Population & Proportion & Sample Size \\
\hline Students & 19,141 & 0.890 & 335 \\
\hline Staff (Academic Staff \& Non-academic) & 2,321 & 0.110 & 41 \\
\hline Commercial service providers & 50 & 0.002 & $1(10)$ \\
\hline Total & 21,512 & 1.000 & $377(386)$ \\
\hline
\end{tabular}

\subsection{Instrument of the study}

A structured questionnaire was the instruments used to ascertain the stakeholders' participation in environmental protection activities. The instrument comprised of two sections. Section A focused on the demographic information on the respondents while Section B had 14 Likert type items designed to the level of participation in environmental protection activities divided into three groups (efficient transportation, energy saving and waste management). Responses on these questions were provided by the respondents based on 5 points scale Likert to indicate: 1-Never, 2-Rarely, 3-Sometimes, 4-Often and 5-Always. The respondents were located by the researcher and research assistants who are students and colleagues in other departments on the campus.

\subsection{Validation and Reliability of Instrument}

The instrument for the data collection was validated by experts in the field of environmental management. In line with the suggestion of van Belle (2002) that a sample size of 10-30 is adequate for a pilot study involving one-toone survey, 15 copies of the questionnaire were distributed to some students and staff who were not a part of the actual study for a pilot survey. Suggestions raised by them were incorporated to improve the final copy of the questionnaire distributed for the actual study. The test of reliability, Cronbach alpha yielded a reliability coefficient of 0.83 (George \& Mallery, 2003 as cited in Gliem \& Gliem, 2003). Thus, the instrument was considered valid and reliable for the study.

\subsection{Analysis of Results}

Data collected were summarized and computed using descriptive statistics (frequency and percentages) and inferential statistics (Kruskal Wallis).

\section{Results and Discussion}

\subsection{Demographic Characteristics}

Respondents for the study comprised of three internal stakeholders in the study area namely, students, staff (both academic and non-academic), and commercial service providers. As presented in Table 2, male respondents have the highest representation of 67.3 per cent while their female counterparts accounted for the remaining 32.7 per cent of the respondents. Available statistics for 2016/2017 session retrieved from Directorate of Academic 
Planning (DAP) of the institution shows that male and female students on the campus are in proportions of 72.8 per cent and 27.2 per cent respectively. On the other hand, the statistic shows that male and female staff accounted for 70.2 per cent and 29.8 per cent respectively. On the average, 72.3 per cent and 27.7 per cent of the campus stakeholders are male and female respectively. From this result, it is evident that male respondents are more than female on the campus, which is closely related to the percentages that participated in the study. The reason for this difference is as a result of the science and technological specialization of the university. Students represented 87.3 per cent of the respondents that participated in the study, followed by 10.3 per cent members of staff and 2.4 per cent commercial service providers. The skewness of proportion towards the students is because they are more in number than both staff and commercial service providers as reported in the sample size calculated in the third section.

Table 2: Cross Tabulation of Demographic Characteristics

\begin{tabular}{|c|c|c|c|c|c|c|c|c|c|c|c|}
\hline & \multicolumn{2}{|c|}{ Student } & \multicolumn{2}{|c|}{$\begin{array}{c}\text { Academic } \\
\text { staff }\end{array}$} & \multicolumn{2}{|c|}{$\begin{array}{c}\text { Non-academic } \\
\text { staff }\end{array}$} & \multicolumn{2}{|c|}{$\begin{array}{c}\text { Commercial } \\
\text { Service providers }\end{array}$} & \multicolumn{2}{|c|}{ All } \\
\hline & & Freq & $\%$ & Freq & $\%$ & Freq & $\%$ & Freq & $\%$ & Freq & $\%$ \\
\hline \multirow[t]{2}{*}{ Gender } & Male & 190 & 66.0 & 21 & 77.8 & 4 & 57.1 & 7 & 87.5 & 222 & 67.3 \\
\hline & Female & 98 & 34.0 & 6 & 22.2 & 3 & 42.9 & 1 & 12.5 & 108 & 32.7 \\
\hline \multicolumn{2}{|l|}{ Total } & 288 & 100 & 27 & 100 & 7 & 100 & 8 & 100 & & 100.0 \\
\hline \multicolumn{2}{|c|}{ Per cent } & & 87.3 & & 8.2 & & 2.1 & & 2.4 & & 100.0 \\
\hline
\end{tabular}

\subsection{Level of Participation of Stakeholders in Environmental Sustainability}

Table 3 shows the level of participation of stakeholders in environmental sustainability based on the mean values of individual items of the questionnaire which are in three areas namely: efficient transportation, energy saving and waste management. 5 shows the level of participation of male and female in environmental sustainability in these areas. Participation is on a scale of $1.00-5.00$ (low - very high).

Efficient transportation: As displayed in Table 3, boarding of public or mass transit to/from work has an equal mean of 3.56 rated high for both male and female, which depicts that they both have an equal level of participation in this activity. Telecommuting or working from home as part of the working day from your personal computer has close mean values of 3.01 and 3.02 for both female and male respectively, to show equal level of participation that is moderate for both genders. Using video and/or web conferencing is moderate for female (2.61) but low for male (2.47). Trekking within the campus especially short distances is very high for the two genders: female (4.43) and male (4.29). The average mean values for the activities indicates that female (3.40) stakeholders have a moderate level of participation in environmental management using efficient transportation activities just like male (3.34) stakeholders.

Energy saving: Table 3 shows that the use of energy saving bulb and other devices is high for female and male with means of 3.93 and 3.91 respectively. Switching off the electric bulb, electronics and appliances when not in use is also high for both gender, where female have mean, 3.84 and male, 4.00. Using only essential electrical appliances when there is electricity supply is very high for the female (4.24) but high for male (4.09). High level of participation in environmental activities is shown by both female (3.98) and male (3.99) in their preference for the usage of internet/TV to access news rather than purchasing a daily newspaper. Generally, female and male to a high extent participate in environmental management by being involved in energy saving activities considering the average mean values which are 3.96 and 3.99 respectively.

Waste management: Table 3 also reveals that female and male stakeholders to a high extent do not dispose items which could be repaired or reused. This is evident from the mean values of their responses to the tune of 3.67 and 3.75 for both female and male respectively. Nonetheless eating at fast-food restaurants rather than take-away is rather low for the female (2.59) compare to the male (3.07) which is moderate. Also, double-sided printing is moderately high for the female while it is high for male (3.45). Recycle or reuse of paper or any other materials is moderate for female (2.88) and male (2.92). Lastly, using soft copy documents rather printed ones when appropriate is high for the two genders; while female stakeholders have a mean value of 3.71, male stakeholders have a mean value of 3.88. On average, participation in environmental management in the area of waste management is moderate for female (3.71) compare to their male (3.88) counterparts who have high level participation. Nevertheless, Aye (2018) stated that female have played an important role in reducing resource use, reusing and recycling resources to minimize waste and excessive consumption.

Summarily, comparing the gender-based ranking of the level of participation of stakeholders in environmental management, the results presented in Table 3 show that the level of participation of male and female is both high in environmental management activities relating to energy saving. Notwithstanding, female show a moderate level of participation for efficient transportation and waste management while the show high participation for waste management and moderate level of participation for efficient transportation. 
Table 3: Stakeholders' Participation in Environment Sustainability

\begin{tabular}{|l|c|c|c|c|}
\hline & \multicolumn{3}{|c|}{ Female } & Male \\
\hline & Mean & Interpretation & Mean & Interpretation \\
\hline Efficient Transportation & $\mathbf{3 . 4 0}$ & Moderate & $\mathbf{3 . 3 4}$ & Moderate \\
\hline Carpooling or taking public or mass transit to/from work & 3.56 & High & 3.56 & High \\
\hline $\begin{array}{l}\text { Telecommuting or working from home as part of your working } \\
\text { day from your PC }\end{array}$ & 3.01 & Moderate & 3.02 & Moderate \\
\hline Video and/or web conferencing & 2.61 & Moderate & 2.47 & Low \\
\hline Walking within the campus especially short distances & 4.43 & Very High & 4.29 & Very High \\
\hline Energy Saving & $\mathbf{3 . 9 6}$ & High & $\mathbf{3 . 9 9}$ & High \\
\hline Energy saving bulb and other devices & 3.93 & High & 3.91 & High \\
\hline $\begin{array}{l}\text { Switching off the electric bulb, electronics and appliances } \\
\text { when not in use }\end{array}$ & 3.84 & High & 4.00 & High \\
\hline Using only essential electrical appliances when there is light & 4.24 & Very High & 4.09 & High \\
\hline $\begin{array}{l}\text { Avoid purchasing a daily newspaper (I use Internet/TV } \\
\text { instead) }\end{array}$ & 3.98 & High & 3.99 & High \\
\hline Waste Management & $\mathbf{3 . 2 4}$ & Moderately & $\mathbf{3 . 4 1}$ & High \\
\hline Do not throw away items which could be repaired or reused & 3.67 & High & 3.75 & High \\
\hline Eating at fast-food restaurants rather than take-away & 2.59 & Low & 3.07 & Moderate \\
\hline Printing double-sided & 3.33 & Moderate & 3.45 & High \\
\hline Recycle or reuse of paper or any other materials & 2.88 & Moderate & 2.92 & Moderate \\
\hline Soft copy documents rather printed copy when appropriate & 3.71 & High & 3.88 & High \\
\hline
\end{tabular}

\begin{tabular}{|c|c|c|c|c|}
\hline Very Low & Low & Moderate & High & Very High \\
\hline $1.00-1.80$ & $1.81-2.60$ & $2.61-3.40$ & $3.41-4.20$ & $5.00-4.21$ \\
\hline
\end{tabular}

\subsection{Gender Difference in the level of Participation in Environment Sustainability among Stakeholders}

Table 4 revealed the gender difference in stakeholders' participation in environmental sustainability using the Kruskal-Wallis test. The analyses were conducted for each of the stakeholders (students, academic staff, nonacademic staff and commercial service providers) for each of the three environment sustainability areas followed by a general analysis for all the stakeholders.

4.3.1 Gender difference in the level of participation in environment sustainability among the students

Female students recorded a higher mean score $(X=150.44)$ than their male colleagues $(X=141.43)$ for their level of participation in efficient transportation-related activities but the difference in their means is not statistically significant (female, $n=98$; male, $n=190), X^{2}(n=288) 0.763, p=0.382$. Female students also recorded a higher mean score $(X=145.72)$ than their male colleagues $(X=143.87)$ for energy saving related activities. However, the difference in their means is not statistically significant (female, $n=98 ;$ male, $n=190$ ), $X^{2}(n=288) 0.032, p=0.857$. In addition, male students recorded a higher mean score $(X=152.93)$ than the female students $(X=128.15)$ for waste management actions; the difference in these means is statistically significant (female, $n=98$; male, $n=190), X^{2}(n=288) 5.766, p=0.016$. From all indication, these results show that although there is no significant difference in participation of male and female students efficient transportation and energy saving related activities, there is a significant difference between male and female students' participation in waste management activities. The mean score with which male students' level of participation in waste management is higher than that of female students is to a tune that cannot be said to be due to chance. This implies that male respondents seem to be better waste or resources manager on FUTA campus than female students.

4.3.2 Gender difference in the level of participation in environment sustainability among the academic staff Male academic staff recorded a higher mean score $(X=14.71)$ for efficient transportation-related activities compare to the female academic staff $(X=11.50)$. The difference in the means for the two gender is not statistically significant (female, $n=6$; male, $n=21), X^{2}(n=27) 0.783, p=0.373$. Similarly, male academic staff recorded a higher mean score $(X=14.38)$ compare to the female students $(X=12.67)$ for energy saving activities but the difference in their means is not statistically significant (female, $n=6$; male, $n=21), X^{2}(n=27) 0.227, p=$ 0.634 . However, female academics have a higher mean score $(X=19.50)$ than their male colleagues $(X=12.43)$ for waste management actions. Nonetheless the difference in their means is not statistically significant (female, $\mathrm{n}$ $=6$; male, $n=21), X^{2}(n=27) 3.781, p=0.052$. These results show that the difference in the mean score for male and female participation in environmental management activities are not remarkably high enough to justify a disparity in gender difference among academic staff. This is probably due to the contribution of education which makes both male and female to be aware of the environment and act in a way to protect it. 
4.3.3 Gender difference in the level of participation in environment sustainability among the non-academic staff Female non-academic staff showed a higher mean score $(X=4.57)$ than the male non-academic staff $(X=3.50)$ in respect to efficient transportation but the difference is not statistically significant (female, $n=3 ;$ male, $n=4$ ), $X^{2}(n=7) 0.500, p=0.480$. Similarly, female non-academic staff showed a higher mean score $(X=4.33)$ than their male colleagues $(X=3.75)$ in respect to energy saving. Difference in the means is not statistically significant (female, $\mathrm{n}=3$; male, $\mathrm{n}=4), \mathrm{X}^{2}(\mathrm{n}=7) 0.132, \mathrm{p}=0.716$. In the same vein, female non-academic staff recorded a higher mean score $(X=4.67)$ for waste management actions than the male non-academic staff $(X=3.50)$. However, the difference in their means is not statistically significant (female, $\mathrm{n}=3$; male, $\mathrm{n}=4$ ), $X^{2}(n=7) 0.519, p=0.471$. While female non-academic staff have higher mean values for the three group environmental management activities, these mean values do not make them significantly higher than male nonacademic staff in their level of participation in environmental management activities.

4.4.4 Gender difference in the level of participation in environment sustainability among the commercial service providers

The results presented in the Table 4 show that female commercial service providers recorded a higher mean score $(X=6.00)$ relative to the male commercial service providers $(X=4.29)$ with respect to efficient transportation although their difference in means is not statistically significant (female, $n=1 ;$ male, $n=7), X^{2}(n=8) 0.429, p=$ .513. In the case of energy saving, male commercial service providers have a higher mean score $(X=4.64)$ compared to the female commercial service providers $(X=3.50)$. The difference in their means is not statistically significant (female, $n=1$; male, $n=7), X^{2}(n=8) 0.195, p=.659$. In the same way, male commercial service providers indicated a higher mean score $(X=4.57)$ compared to the female commercial service providers $(X=4.00)$ for waste management but the difference in their means is not statistically significant female, $n=1 ;$ male, $n=7$ ), $\mathrm{X}^{2}(\mathrm{n}=8) 0.048, \mathrm{p}=0.827$. Evidently, it can be said that all commercial service providers on FUTA campus, whether male or female are, to confidence level, at almost the same level in terms of environmental management on the campus.

Table 4: Gender Difference in Stakeholders' Participation in Environment Sustainability

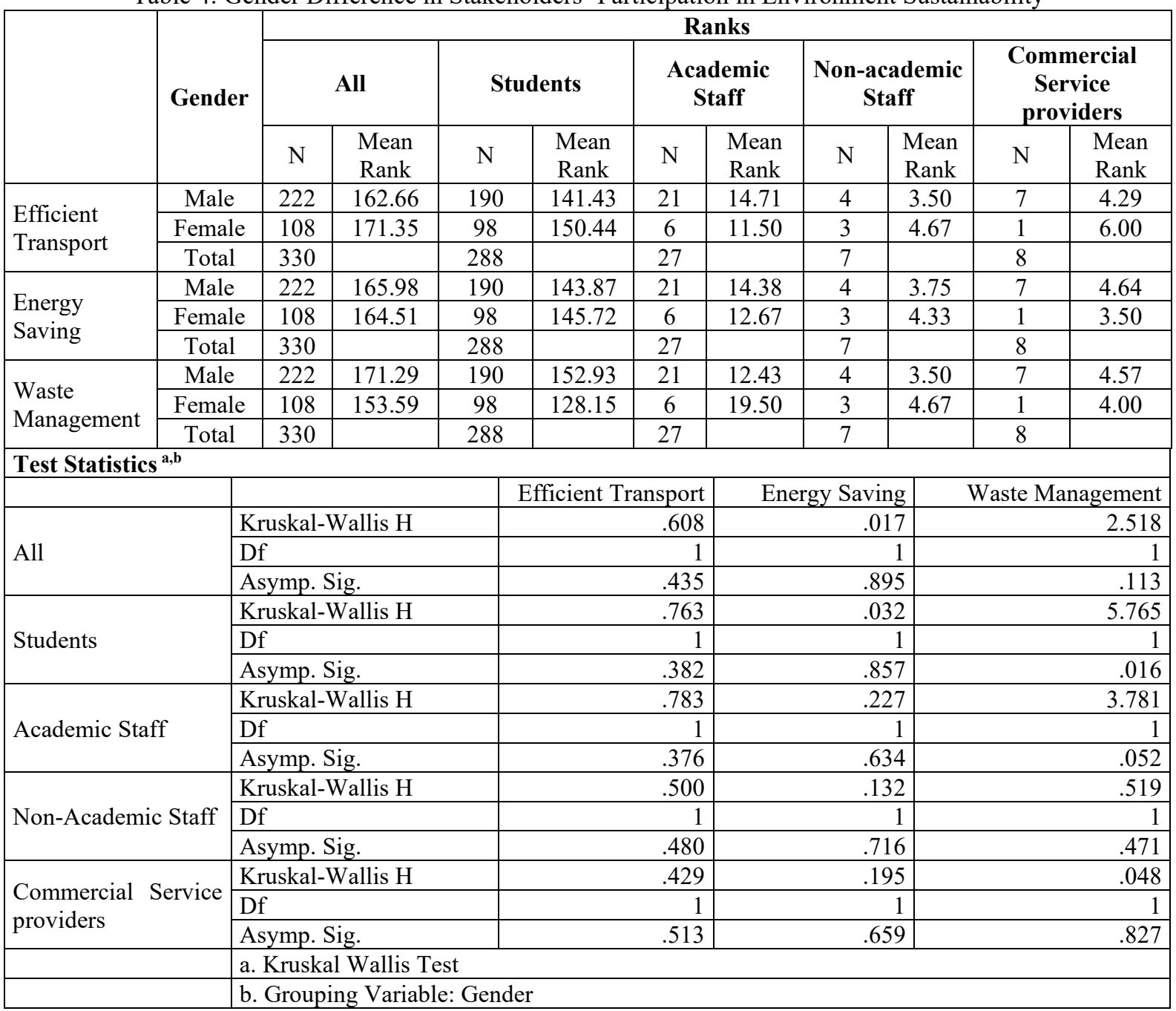




\subsection{Hypothesis Testing}

The only hypothesis in the study is as stated in the null form below.

$H_{0}$ : $\quad$ There is no significant difference in the level of participation in environmental management among male and female in the study area

The test results displayed in Table 5 revealed that there is no statistically significant difference in the level of participation in environmental management among male and female in the study area (female, $\mathrm{n}=108 ;$ male, $\mathrm{n}=$ $222), X^{2}(n=330)=0.247, p=0.619$. Since significant probability $(0.619)$ is greater than significant level $(0.05)$. This means that the null hypothesis one $\left(\mathrm{H}_{0}\right)$ which states that there is no significant difference in the level of participation in environmental management among male and female in the study area should be accepted. Female and male show no major differences in their level of participation in environmental management on FUTA campus. Notwithstanding, male stakeholders recorded a higher mean score $(X=167.32)$ compared to female $(X=$ 161.76).

Sivamoorthy, et al. (2013) found that the level of awareness for environmental management is higher for males based on their involvement than for females although only students were involved in the study. It is however, contrary to the discovery in Akkor and Gunduz (2018), which indicates that female students have higher environmental attitudes and are more sensitive to the environment than male students are. Women have a significant role to play in promoting sustainable development as envisaged in the MDGs, especially those related to environmental protection (Aye, 2017). The available evidence from this study indicates that both male and female have individual roles to play in any environment. These relate to their level of consumption of environmental resources, the role they play in the society, their exposure and knowledge level and the importance they place on making their domain safe for themselves and others. When the environment is safe for them, it is also safe for others.

Table 5: Hypothesis Testing

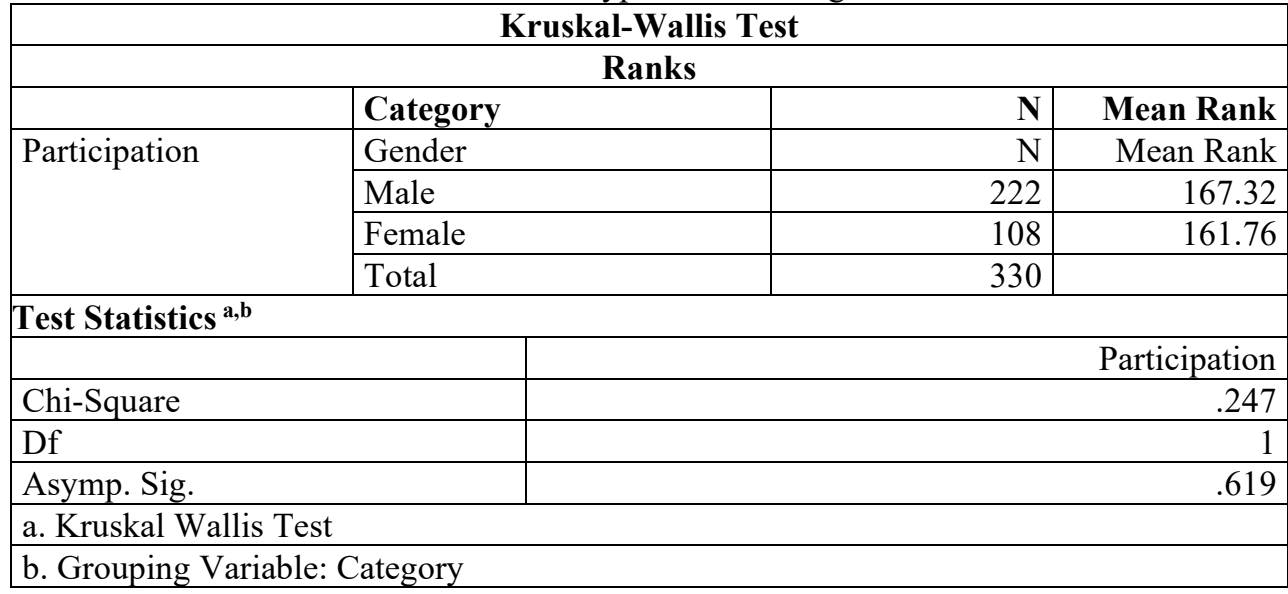

\section{Conclusion and Recommendations}

\subsection{Conclusion}

The study has assessed stakeholders' participation in environmental management in the university system in Nigeria from a gender perspective. It can be concluded that the level of participation of male and female is both high in activities relating to energy saving. Female show a moderately high level of participation for efficient transportation and waste management while the male show high participation for waste management and moderately high participation for efficient transportation. Though gender-wise university stakeholders are not at the same level of participation in environmental management, the differences recorded are not significant except for waste management among the students in which male level of participation in environmental management is significantly different from their female counterparts.

\subsection{Recommendations}

The study suggested that all stakeholders on university campus irrespective of their gender should be equipped with knowledge and skill that will make them effectively and efficiently participate in environmental management through deliberate and periodic training. Also, university management should show commitments to this undertaking by investing in research to generate new initiatives for the purpose of facing future dynamism.

\section{Reference}

Aasa, O. P. (2019). Analysis of greening project initiatives in The Federal University of Technology, Akure, Nigeria (Unpublished Master's Thesis). The Federal University of Technology, Akure, Nigeria. 
Adebo G. M. \& Ajewole, O. C. (2012). Gender and the Urban Environment: Analysis of Willingness to pay for Waste Management Disposal in Ekiti-State, Nigeria. American International Journal of Contemporary Research, 2 (5), 228-236.

Akkor, O. \& Gunduz, S. (2018). The study of university students' awareness and attitude towards environmental education in Northern Cyprus. EURASIA Journal of Mathematics, Science and Technology Education, 14(3), $1057-1062$.

Agwu, J. \& Okhimamhe, A. A. (2009). Gender and climate change in Nigeria: A study of four communities in North-Central and South-Eastern Nigeria. Lagos: Heinrich Böll Stiftung.

Aye T.T. (2018). The role of rural women in environmental management in Myanmar: A Case Study of Ngaputaw Township. Open Science Journal, 3 (1).

Castaneda, I., Aguilar, C. \& Rand, A. (2013). Measurement and reporting: Important elements of gender mainstreaming in environmental policies. Cornell Journal of Law and Public Policy, 22 (3), Article 5. Available at: http://scholarship.law.cornell.edu/cjlpp/vol22/iss3/5

Chukwu, M. N. (2014). A Study on Gender Involvement in Environmental Protection in Pedro Village, Lagos. Academic Journal of Interdisciplinary Studies, 3 (7), 21-24. DOI: 10.5901/ajis.2014.v3n7p20

European Institute for Gender Equality (EIGE) (2016). EIGE brief. Luxembourg: Publications Office of the European Union. Available at: http://europa.eu

European Institute for Gender Equality (EIGE), 2016). Gender in environment and climate change. Global environment facility, investing in our planet: Gender mainstreaming, 2009.

Gender Tool Box (March, 2016). Gender and the Environment

Haartman, R. V \& Sammalisto, K. \& Lozano, R. \& Blomqvist, P. (2017). A longitudinal comparison of sustainability learning between men and women in engineering and nursing programmes. Sustainability, 9 (8), 1-10.

IUCN (2013). The Environment and Gender Index (EGI) 2013 Pilot. Washington, D.C.: IUCN.

Johnsson-Latham, G. (2007). A study on gender equality as a prerequisite for sustainable development. Report to the Environment Advisory Council, Sweden, 2007 (2).

Kassinis, G. Panayiotou, A. Dimou, A. Katsifaraki, G. (2016). Gender and environmental sustainability: A longitudinal analysis. Corporate Social Responsibility and Environmental Management, 23 (6), 399-412.

Luna, M., Aguilar, L., Gilligan, M., Owren, C., Prebble, M. \& Westerman, K. (2015). Women in environmental decision making: Case studies in Ecuador, Liberia, and the Philippines. The Global Gender Office of IUCN, in collaboration with Conservation International.

OECD (2019). Policy coherence for sustainable development and gender equality: Fostering an integrated policy agenda.

Prebble, M. (2015). Women's participation in environmental decision-making: Developing a new global dataset with the IUCN Global Gender Office (master thesis). Duke University.

Sivamoorthy, M., Nalini, R., \& Satheesh, K. (2013). Environmental awareness and practices among college students. International Journal of Humanities and Social Science Invention, 2 (8), 2319 - 7722.

Thomas, D., Eugene, A. R., \& Richard, Y. (2007). Driving the human ecological footprint. The Ecological Society of America Research Communications, 5(1) 13-18.

van Belle, G. (2002). Statistical rules of thumb. New York, USA: John Wiley.

Vaughter, P., Wright, T., McKenzie, M., \& Lidstone, L. (2013). Greening the Ivory Tower: A Review of Educational Research on Sustainability in Post-Secondary Education. Sustainability, 5(5), 2252-2271. DOI:10.3390/su5052252. 